\title{
ПРОБЛЕМНЫЕ АСПЕКТЫ ВНЕДРЕНИЯ МСФО В РОССИИ
}

\begin{abstract}
Аннотация: Присоединение Российской Федерации к Всемирной торговой организации (далее - ВТО), интеграция российского бизнеса в мировую экономику диктует необходимость изучения и использования универсального языка бизнеса, понятного всему миру - Международных стандартов финансовой отчетности. Практика применения международных стандартов финансовой отчетности доказала, что они позволяют обеспечить максимальную полезность финансовой отчетности для широкого круга пользователей, так как способны раскрывать достаточный для всех участников рынка объем финансовой информации. В статье рассматриваются основные трудности и проблемы, которые обнаружились при внедрении в российскую практику международных стандартов финансовой отчетности, отмечается, что при внедрении международных стандартов финансовой отчетности в российскую практику бухгалтерского учета нужно учитывать некоторые отличия международных стандартов финансовой отчетности от российских стандартов бухгалтерского учёта, обосновывается, что одним из важных отличий является применение принципа приоритета содержания над формой.
\end{abstract}

Ключевые слова: МСФО, МСБУ, финансовая отчетность, ПБУ, нормативное регулирование, консолидированная отчетность, Центральный банк, Министерство финансов, ФО, Фонд НСФО.

DOI: 10.7256/1994-1471.2014.5.9761

$\mathrm{M}$ еждународные стандарты финансовой отчетности (далее - МСФО) - это унифицированный набор принципов и требований к составлению и раскрытию информации в отчетности предприятия. Главная задача МСФО - обеспечить сопоставимость данных о деятельности одной компании с другой.

Финансовая отчетность предприятий разных стран имеет определенные отличия, обусловленные социальными, экономическими и политическими факторами. Отличия в подходах к содержанию финансовых отчетов значительно усложняли анализ информации и принятия решений в условиях развития международной торговли, транснациональных корпораций, глобализации финансовых рынков.

Для обеспечения гармонизации финансовой отчетности 29 июня 1973 года создан Комитет по Международным стандартам бухгалтерского учета на основе соглашения профессиональных организаций бухгалтеров Австралии, Великобритании, Ирландии, Канады, Нидерландов, Германии, Мексики, США, Франции и Японии. За время деятельности Комитета был издан 41 международный стандарт бухгалтерского учета.

МСФО представляют собой важную международную систему общепризнанных принципов бухгалтерского учета, информация ко-

торого предназначается для представления различным организациям и лицам, интересующимся результатами деятельности и финансовым состоянием составителя отчетности, формируемая по правилам международных стандартов бухгалтерского учета.

Они широко применяются и приняты в качестве основы подготовки финансовой отчетности во многих странах мира, вносят большой вклад в совершенствование и гармонизацию финансовой отчетности. В странах с недостаточно развитой законодательной системой в области бухгалтерского учета МСФО используются как основа для национальных стандартов.

Следует отметить, что первоначально главной целью гармонизации было формулирование, издание и совершенствование международных стандартов бухгалтерского учета, которые следует соблюдать при представлении финансовых отчетов. Однако национальные системы учета различных стран не всегда могли быть сближены с международными стандартами бухгалтерского учета (далее МСБУ). Поэтому в 2000 году Совет по международным стандартам бухгалтерского учета переориентировал свои цели на определение методов оценки и подходов к представлению информации в финансовой отчетности и на

(C) Кожевникова Светлана Игоревна

* Аспирантка кафедры финансового права, Московский государственный юридический университет имени О.Е. Кутафина (МГЮА)

[svetlanak0307@mail.ru]

119017, Россия, г. Москва, ул. Большая Ордынка, д. 24. 
сближение национальных стандартов финансовой отчетности с международными. Поэтому МСБУ были переименованы в МСФО ${ }^{1}$.

Напомним, что Президент России 27 июля 2010 года подписал Федеральный закон «0 консолидированной финансовой отчетности» от 27.07.2010 №208-Ф3, устанавливающий требования к составлению и публикации консолидированной финансовой отчетности в соответствии с МСФО для кредитных, страховых и иных организаций, ценные бумаги которых допущены к обращению на торгах фондовых бирж и иных организаторов торговли на рынке ценных бумаг. Срочное принятие закона в 2010 году было обусловлено решением «Большой двадцатки» о повсеместном переходе на МСФО не позднее июля 2011 года. Именно такой срок был установлен для завершения конвергенции международных и американских стандартов бухгалтерского учёта.

Итак, с 2012 года применение МСФО в России было установлено федеральным законом, а порядок применения установлен нормативными документами Министерства финансов Российской Федерации (далее - Минфин РФ). Заметим, что в 2011, 2012 и 2013 годах в указанный закон были внесены изменения. Особенно значима, на наш взгляд, редакция от 23.07.2013 (ФЗ № 251). Основные новеллы внесены в ст. 30 Ф3 «0 консолидированной финансовой отчетности», в новой редакции которой отмечается, что в обязательном порядке годовая консолидированная финансовая отчетность представляется участникам организации, в том числе акционерам, а также в Центральный банк Российской Федерации.

В 2012 году на территории РФ были признаны к применению 29 Международных стандартов финансовой отчетности (IAS) (с 1 по 41 , кроме 3, 4, 5, 6, 9, 13, 14, 15, 22, 25, 30, 35), 8 Международных стандарта финансовой отчетности (IFRS) (с 1 по 8), 10 Разъяснений ПКР (SIC), 16 Разъяснений КРМФО (IFRIC).

В текущем 2013 году обязательными для применения наряду с требованиями измененных стандартов стали новые МСФO (IFRS) 10, 11, 12 консолидационного «Пакета пяти» стандартов и МСФО (IFRS) 13 «Оценка справедливой стоимости». Другие обязательные изменения носят более точечный характер, поэтому их влияние ограничено.

Ключевым новшеством 2013 года стал консолидационный «Пакет пяти» стандартов. Совет по МСФО выпустил его в мае 2011 года с целью унификации требований по подготовке отдель-

Миславская Н.А., Поленова С. Н. Международные стандарты учета и финансовой отчетности: М., Дашков и Ко, 2011. С. 175. ной и консолидированной отчетности, а также для максимального сближения с US GAAP.

Однако, как отражено на официальном сайте Минфина РФ, «Фонд МСФО отказался от права на защиту своих авторских прав в отношении Международных стандартов финансовой отчетности на территории Российской Федерации. Фонд МСФО сохраняет за собой все права за пределами указанной территории» ${ }^{2}$.

Возможно, это означает, что отчетность, сформированная на территории РФ, не будет признаваться соответствующей МСФО на территории других стран.

Применение опубликованных Минфином РФ МСФО законно в связи с выполнением всех условий, обязательных для вступления их в силу, в соответствии с Положением о признании Международных стандартов финансовой отчетности и Разъяснений международных стандартов финансовой отчетности для применения на территории Российской Федерации, утвержденным постановлением Правительства Российской Федерации от 25 февраля 2011 г. № 107 «Об утверждении Положения о признании Международных стандартов финансовой отчетности и Разъяснений международных стандартов финансовой отчетности для применения на территории Российской Федерации»:

- официальное получение от Фонда документа международных стандартов;

- экспертиза применимости документа международных стандартов на территории Российской Федерации (далее - экспертиза);

- $\quad$ принятие решения о введении документа международных стандартов в действие на территории Российской Федерации;

- опубликование документа международных стандартов.

Минфин РФ обеспечивает получение от Фонда перевода на русский язык каждого документа международных стандартов.

Экспертиза стандартов МСФО была проведена в отношении признанных и проводится в отношении подлежащих признанию Фондом «Национальная организация по стандартам финансового учета и отчетности», утвержденным Минфином РФ как организацией, имеющей право осуществлять такую экспертизу, так как она выиграла в конкурсе по определению экспертного органа, заявка на который была подана только одним претендентом - Фондом НСФО, в соответствии с Информационным сообщением Минфина РФ от 21.07.2011 года «0 заключении соглашения об экспертизе приме-

Документы МСФО. [Электронный ресурс]. Официальный сайт Министерства финансов PФ. URL: http:// www1.mi№fio..ru/ru/accou№ti№g/mej_sta№dart_fo/docs/ i№dex.php?pg4=1 
нимости Международных стандартов финансовой отчетности и Разъяснений международных стандартов финансовой отчетности».

Принятие решения о введении документа международных стандартов в действие на территории Российской Федерации принимается в отношении документа в целом. В случае если в отношении отдельных положений документа международных стандартов решение о применимости на территории Российской Федерации не может быть принято, то решение о введении такого документа в действие на территории Российской Федерации принимается в отношении документа с изъятием указанных положений. Данное решение принимает Минфин РФ по согласованию с Федеральной службой по финансовым рынкам, с Центральным банком Российской Федерации.

Опубликование стандарта МСФО осуществляется в журнале «Бухгалтерский учет» или на официальном сайте Минфина РФ. Стандарт считается опубликованным, если не определен иной порядок вступления его в силу, со дня его официального опубликования (п. 7, гл. 1 № 107). Журнал «Бухгалтерский учет» является официальным источником публикации в соответствии с Приказом Минфина РФ от 25.11.2011 года №160н «0 введении в действие Международных стандартов финансовой отчетности и Разъяснений международных стандартов финансовой отчетности на территории Российской Федерации».

В соответствии с действующим законодательством, инициативное применение МСФО не предусмотрено, обязательное применение МСФО предусмотрено на основании ст. 2 Федерального закона от 27.07.2010 № 208-Ф3 «0 консолидированной финансовой отчетности» для организаций:

1) кредитных;

2) страховых;

3) иных организаций, ценные бумаги которых допущены к обращению на организованных торгах;

4) всех организаций, составляющих консолидированную отчетность в соответствии с законодательством РФ или её учредительными документами.

При внедрении международных стандартов в российскую практику бухгалтерского учета нужно учитывать некоторые отличия МСФО от российских стандартов бухгалтерского учёта (далее - РСБУ).

Одним из важных отличий является применение принципа приоритета содержания над формой. Для практики МСФО он является обязательным, так как содержание операций не всегда соответствует тому, какими они представляются на основании юридической формы этих операций. По правилам международных стандартов, бухгалтерские проводки отражаются в соответствии с экономической сущностью операции. В российской системе бухгалтерского учета все операции должны учитываться строго в соответствии с юридической формой. Это разночтение при переходе от РСБУ к МСФО служит серьезным препятствием для компаний.

Еще одно отличие заключается в принципе отражения затрат в МСФО, механизм которого существенно отличается от российских стандартов. По правилам международных стандартов, необходимо учитывать принцип соответствия, согласно которому затраты отражаются в периоде ожидаемого получения дохода. По российским правилам учета затраты отражаются только после выполнения определенных требований в отношении документации. Это условие часто не позволяет российским компаниям учесть все хозяйственные операции, относящиеся к определенным периодом. Данная особенность РСБУ также приводит к значительным трудностям при переходе к международным стандартам.

Существуют и другие отличия, используемые в настоящее время в российской практике и оказывающие существенное влияние на всю схему работы РСБУ. Ниже приведем основные из них:

- по международным стандартам неденежные статьи баланса должны пересчитываться на инфляцию в гиперинфлируемой экономике. В РСБУ требование пересчета на инфляцию отсутствует как таковое;

- для МСФО отчет о движении денежных средств является обязательным для представления в финансовой отчетности с включением информации по сегментам (виды продукции и регионы). В российской практике такой отчет чаще всего не дает реальной картины действительности, а потому предоставляется с финансовой отчетностью крайне редко;

- при соблюдении МСФО крайне важно, чтобы управленческие расходы отражались отдельно и не включались в себестоимость продукции. Согласно РСБУ управленческие расходы вполне возможно включить в себестоимость продукции;

- в соответствии с международными стандартами, размещенный капитал должен отражаться в балансе, а деловая репутация компании - учитываться и оцениваться. В российской практике учета такое понятие, как размещенный капитал, отсутствует, а деловая репутация никак не отражается.

Таких отличий достаточно, и все они в своем большинстве носят концептуальный, миро- 
воззренческий характер. Так, по утверждению И. А. Власовой, «Международные стандарты требуют не четкого соблюдения инструкций и знания всех проводок, а понимания сути происходящих операций и умения использовать имеющиеся правила и полученную информацию для повышения эффективности работы компании» ${ }^{3}$.

Еще одним препятствием при переходе к международным стандартам является несовершенство российской законодательной базы. В последнее время Минфин РФ издал большое количество нормативных документов, в основном Положения по бухгалтерскому учету (далее - ПБУ), по своему содержанию довольно близких к МСФО и отражающих основные принципы международных стандартов. Однако в российских стандартах до сих пор отсутствуют определения множества базовых понятий, а также встречаются противоречия в нормативных документах различных уровней.

Заслуживает интерес исследование, которое было проведено журналом «МСФО на практике» совместно с аудиторско-консалтинговой компанией «Бейкер Тилли Русаудит» «Практика применения МСФО в России в 20092011 гг.». В ходе исследования выявлены основные причины составления отчетности по МСФО отечественными компаниями, оценены сроки подготовки отчетности и проведения аудита, проанализированы наиболее актуальные задачи в области применения МСФО и подходы к выбору программных продуктов. В опросе приняли участие более 200 компаний реального сектора экономики.

В результате исследования выяснилось, что наиболее актуальной проблемой для российских компаний на данный момент является сокращение сроков подготовки отчетности по национальным стандартам ${ }^{4}$.

В первую очередь это объясняется тем, что большинство компаний применяют метод трансформации российской отчетности в международную. В этом случае сроки подготовки МСФО-отчетности напрямую зависят от даты закрытия российской бухгалтерии. По этим же причинам не менее актуальна проблема сближения российских и международных правил учета. Чем более близки будут эти учетные

Власова И.А. Актуальные вопросы развития международных стандартов финансовой отчетности [Электронный ресу URL: pc]. //Электронный научный журнал Управления экономическими системами. № 10 , 2012. http://www.uecs.ru/logistika/item/1590-2012-1012-05-23-05

4 Почему компании предпочитают отчетность по МСФО // Учёт. Налоги. Право. № 26, 2011. С. 7. системы, тем меньше потребуется корректировок для трансформации отчетности. Указанная проблема является основной для компаний с выручкой «от 6 до 15 млрд руб.». На возможность сближения учета по РСБУ и МСФО влияют многие факторы: отраслевые особенности, собственники (российские или иностранные), количество компаний, включаемых в консолидированную отчетность, применяемое программное обеспечение и многое другое. Наиболее оптимальное решение, по мнению ряда специалистов, - сблизиться по ряду позиций, но не в полном объеме 5 .

Для компаний «средних» сегментов (категории с выручкой «от 3 до 6 млрд руб.» и «от 6 до 15 млрд руб.») задача сокращения сроков составления отчетности по МСФО практически сравнялась с задачей интеграции учета по МСФО и управленческого учета. Эти компании активно используют отчетность, подготовленную в соответствии с МСФО, для управленческих целей, выстраивают на ее основе систему бюджетирования. А для таких целей необходима актуальная информация.

Для российских компаний, в первую очередь тех, которые составляют отчетность впервые, также актуальны конкретные учетные задачи. Актуальные проблемы, возникшие на данном этапе, связаны с оценкой активов (в частности, основных средств, дебиторской задолженности), учетом лизинговых операций (финансовой аренды), расчетом ставки дисконтирования, расчетом отложенных налогов, отражением резервов.

Среди прочих проблем, возникающих с подготовкой отчетности, были названы также сроки проведения аудита. Большинству компаний необходимо подтверждение соответствия финансовой отчетности требованиям международных стандартов независимым аудитором.

Собственники и руководство предприятий признают, что сама по себе отчетность по МСФО не гарантирует притока инвестиций, тем более величина чистой прибыли, полученной по правилам международных стандартов, будет всегда ниже, чем по российским правилам. Это обусловлено применением требования «осмотрительности» ко всем международным стандартам. Под вопросом также остается соответствие ожидаемых положительных экономических последствий от нововведения серьезным трудовым и финансовым затратам, которые обязательно возникнут у предприятия при формировании отчетности по МСФО.

5 Практика применения МСФО в России: результаты исследования // МСФО на практике, № 6, 2011. 
Разумеется, что данное утверждение справедливо лишь для тех компаний, которые сегодня не имеют законодательной обязанности формировать отчетность по МСФО, а самостоятельно принимают данное решение. В настоящий момент внедрение МСФО в России в первую очередь интересно тем компаниям, которые пытаются выйти на мировой рынок, имеют зарубежных акционеров либо хотят привлечь иностранные инвестиции.

В России отчетность формируется, в основном, для государственных органов, в частности для налоговых и статистических. Отчетность согласно МСФО отвечает интересам рыночной экономики. Отчетность по РСБУ четко стандартизирована, а по МСФО - в каждом финансовом институте уникальна и неповторима. Поэтому, можно сказать, что то, что понятно государству как регулирующему органу, то не поймет инвестор.

Для того чтобы угодить и тем, и другим, видится следующее решение проблемы: составлять две формы финансовой отчетности. Такой способ принят во многих странах Европы. И он является довольно действенным, хоть и более трудоемким. Или, возможно, придумать такую отчетность, которая будет совмещать в себе данные для внутреннего регулятора и внешних пользователей.

В любом случае, должны существовать специальные внутренние стандарты финансовой отчетности, что является обычной практикой в мировой финансовой системе, поскольку связано с необходимостью защиты внутренних финансовых интересов.

МСФО позволяет показывать достоверную, непредвзятую и прозрачную отчетность, которая будет отражать реальную картину деятельности предприятия. Основываясь на МСФО и собственное профессиональное мышление, бухгалтер сможет прийти к нужному решению, а не искать лазейки в четко прописанных правилах, которые позволили бы обойти какие-либо базовые положения ${ }^{6}$.

МСФО, с одной стороны, не являются жесткими и строгими стандартами и позволяют принимать решения самим бухгалтерам, но в то же время они несут в себе глубокий смысл.

Естественно, переход на МСФО - это затратная часть бюджета компании, которая будет включать в себя и переобучение сотрудников, и программное обеспечение, и аудит отчетности. Но затраты на начальном этапе могут принести большие доходы в будущем.

\footnotetext{
Канбекова Э. Введение в МСФО. Различия принципов учета и отчетности в разных странах, проблемы их гармонизации. Проблемы адаптации МСФО в России. [Электронный ресурc]. URL: http://www.audit-it.ru/.
}

Переход российских компаний на МСФО важен не только инвесторам, но и руководству компаний, и государству.

Государству это важно, так как организации, применяющие МСФО, будут привлекать иностранных клиентов, соответственно, это оживит российскую экономику и увеличит поступления в бюджет.

Руководство компаний будет получать достоверную, полную и объективную информацию финансовой отчетности, не прибегая к дополнительным аналитическим операциям.

МСФО значительно сложнее российских правил бухгалтерского учета и требуют от финансистов большей профессиональной подготовки и знаний. Это предопределяет рост требований к профессиональной подготовке и уровню квалификации финансовых и учетных работников, обеспечивающих ведение бухгалтерского учета и составление финансовой (бухгалтерской) отчетности. Нужны квалифицированные специалисты, которые могут понимать и применять МСФО. Причем речь идет не только о подготовке отчетности, но и об использовании и понимании ее.

Однако надо отдавать себе отчет в том, что за короткий срок невозможно подготовить достаточное количество специалистов, способных удовлетворить растущий спрос на услуги в этой сфере. Подготовка даже одного высококвалифицированного специалиста в области Международных стандартов финансовой отчетности требует определенного времени. Необходимо понимать, что обучение может составить существенную сумму затрат для предприятий, так же как и составление отчетности по МСФО.

Переход на МСФО требует очень серьезной, большой и кропотливой подготовки. Причем подготовки не только компаний и профессионального сообщества, но и в не меньшей степени регулирующих органов и инвестиционного сообщества. Нужно привлечь пользователей финансовой отчетности к проблеме внедрения МСФО.

Для обеспечения надежности бухгалтерской отчетности по МСФО потребуются хорошо подготовленные профессионалы на предприятиях, а также компетентные и независимые аудиторы. Аудиторы представляют собой важнейшее связующее звено между предприятием и иностранными инвесторами, так как качество предоставляемой инвестору информации напрямую зависит от квалификации аудитора и качества его работы.

К проблемам высшего образования МСФО можно отнести нехватку квалифицированного преподавательского состава. Опыт высшего образования за рубежом, когда занятия в группах ведут практикующие аудиторы и бухгалте- 
ры, может быть очень полезным нашим учебным заведениям.

Систему курсов высших учебных заведений следует согласовать с программами подготовки профессиональных бухгалтеров и аудиторов, чтобы выпускник по направлению бухгалтерского учета, анализа и аудита имел возможность при наличии практического стажа сразу без дополнительной подготовки сдавать экзамены на профессионального бухгалтера и аудитора.

Для качественной подготовки профессиональных бухгалтеров и аудиторов требуется дальнейшее приближение бухгалтерского образования к международным стандартам ЮНКТАД и Международной федерации бухгалтеров - МФБ (IFAC).

Следующая остро стоящая проблема - языковая. Официальный язык международных стандартов финансовой отчетности - английский, что значительно усложняет работу с обновлениями в стандартах и своевременность их применения. Однако языковой барьер не единственная проблема отсутствия оперативности представления информации. В настоящее время, в связи с отсутствием специализированных русифицированных компьютерных программ, на подготовку отчетности по международным стандартам у предприятий уходит слишком много времени и данные теряют свою актуальность. Распространенная в настоящий момент практика составления финансовой отчетности по МСФО методом трансформации с использованием электронных таблиц не позволяет достичь надлежащего уровня внутреннего контроля над качеством подготовки отчетности.

Сегодня еще нельзя утверждать, что Россия полностью перешла на МСФО. Требование о составлении, представлении и публикации финансовой отчетности по международным стандартам распространяется лишь на часть организаций, причем оно ограничено только применением в отношении консолидированной отчетности. В то же время именно консолидированная отчетность котирующихся компаний, а также банков и страховщиков - это тот продукт, который на рынке востребован инвесторами в первую очередь. Для составления именно этой отчетности применение МСФО имеет принципиальное значение.

За компаниями, попавшими в сферу действия Федерального закон от 27.07.2010 № 208-ФЗ (с изм. от 21.11.2011) «0 консолидированной финансовой отчетности», сохраняется обязанность представления обычной отчетности юридического лица в соответствии с Законом о бухгалтерском учете. Дело в том, что консолидированная отчетность котирующихся компаний имеет узкое применение - только для принятия инвестиционных решений. Она не затрагивает то множество сфер общественных отношений, которых касается бухгалтерская отчетность организаций, составляемая сейчас по российским правилам. Поэтому составление консолидированной отчетности листинговыми компаниями непосредственно по МСФО может служить своеобразной опытной площадкой по применению документов, разработанных не в России. Этот опыт можно впоследствии использовать для разработки нормативных механизмов применения международных документов и в отношении неконсолидированной отчетности, после того как бухгалтерские стандарты будут полностью гармонизированы. В случае реализации указанных мер переход на международные стандарты можно завершить гармонично и безболезненно ${ }^{7}$.

В 2011 г. МСФО приобрели в России официальный статус и вопрос о применении МСФО стал не гипотетическим, а вполне практическим вопросом. На сегодняшний день основной проблемой для отечественных специалистов по МСФО являются не их методологические парадоксы или недоработки, а практические вопросы адаптации и применения существующих норм МСФО к российским предприятиям. Данный переход станет важным шагом на пути обеспечения прозрачности информации, предоставляемой инвесторам российскими компаниями, повышения их конкурентоспособности и облегчения выхода на международные рынки.

\section{Библиография}

1. Миславская Н.А. , Поленова С. Н. Международные стандарты учета и финансовой отчетности. М., Дашков и Ко, 2011.

2. Власова И.А. Актуальные вопросы развития международных стандартов финансовой отчетности // Управление экономическими системами. 2012. № 10.

3 Почему компании предпочитают отчетность по МСФО. // Учёт. Налоги. Право .№ 26, 2011. C. 7.

\footnotetext{
Сухарев И.Р. Значение введения МСФО в России // Бухгалтерский учет. №3, 2012. С. 21.
} 
4. Практика применения МСФО в России: результаты исследования // МСФО на практике. 2011. № 6.

5. Канбекова Э. Введение в МСФО. Различия принципов учета и отчетности в разных странах, проблемы их гармонизации. Проблемы адаптации МСФО в России. [Электронный ресурс]. URL: http://www.audit-it.ru/

6. Сухарев И.Р. Значение введения МСФО в России // Бухгалтерский учет. №3, 2012. С. 21.

\section{References}

1. Mislavskaya N.A. , Polenova S. N. Mezhdunarodnye standarty ucheta i finansovoi otchetnosti: M., Dashkov i Ko, 2011.

2. Vlasova I.A. Aktual'nye voprosy razvitiya mezhdunarodnykh standartov finansovoi otchetnosti // Upravlenie ekonomicheskimi sistemami. 2012. № 10.

3. Pochemu kompanii predpochitayut otchetnost' po MSFO. // Uchet. Nalogi. Pravo .№ 26, 2011. S. 7.

4. Praktika primeneniya MSFO v Rossii: rezul'taty issledovaniya. // MSFO na praktike. 2011. № 6.

5. Kanbekova E. Vvedenie v MSFO. Razlichiya printsipov ucheta i otchetnosti v raznykh stranakh, problemy ikh garmonizatsii. Problemy adaptatsii MCFO v Rossii. [Elektronnyi resurs]. URL: http:// www.audit-it.ru/

6. Sukharev I.R. Znachenie vvedeniya MSFO v Rossii. //Bukhgalterskii uchet. №3, 2012. S.21.

Материал поступил в редакцию 7 октября 2013 г. 